\title{
The development of intestinal lymphoid tissues at the interface of self and microbiota
}

\author{
G Eberl $^{1}$ and M Lochner ${ }^{1}$
}

Intestinal lymphoid tissues face the challenging task of inducing adaptive immunity to pathogens, yet maintaining homeostasis with the enormous commensal microbiota. To that aim, the ancient partnership between self and flora has resulted in the generation of a unique set of lymphoid tissues capable of constant large-scale reformatting. A first set of lymphoid tissues, the mesenteric lymph nodes and Peyer's patches, are programmed to develop in the sterile environment of the fetus, whereas a second set of lymphoid tissues, the tertiary lymphoid tissues, are induced to form by the microbiota and inflammation. The diversity of intestinal lymphoid tissues confers the flexibility required to adapt the number of immune inductive sites to the size of the flora and the extent of the pathogenic threat. The result is a functional superorganism combining self and microbes for the best possible symbiosis.

\section{INTRODUCTION}

The gut-associated lymphoid tissues have been discovered progressively through the distant ages of human history. Lymph nodes (LNs) were first mentioned in the fifth century BC by Hippocrates, and mesenteric LNs (mLNs) in particular were identified by Rufus of Ephesus, a Roman physician during the second and first centuries BC. ${ }^{1}$ During that same period, Galen of Pergamum, another prominent Roman physician of Greek origin, described the lacteals of the small intestines of apes, that is, the mesenteric lymphatic vessels. It was not before the sixteenth century that similar study was reported in human poisoned convicts by Fallopius. The Peyer's patches (PPs) of the small intestine were subsequently discovered in 1677 by the Swiss anatomist Johann Conrad Peyer. Then, in 1884, the Irish zoologist George Edward Dobson completed the characterization of the larger intestinal lymphoid tissues by reporting the existence of PPs in the cecum and colon of a number of small mammals. ${ }^{2}$ The omentum also had its share of lymphoid tissues, or milky spots, discovered in 1963 by Borisov. ${ }^{3}$ However, the omentum-associated lymphoid tissues do not filter lymph from the intestine, but rather from the peritoneal cavity. ${ }^{4}$ And finally, small isolated lymphoid follicles (ILFs) have been reported in the small intestine of rabbits, ${ }^{5}$ guinea pigs, ${ }^{6}$ and humans, ${ }^{7}$ and best studied later in mice. ${ }^{8}$

It is no coincidence that the order of discovery of intestinal lymphoid tissues is also the order of appearance during development, as it happens also to be the order of size. In mouse, mLN anlagen are visible from embryonic day E12.5 and develop into the largest gut-associated lymphoid tissues. ${ }^{9}$ The PPs develop from E15.5 and are more limited in size compared with mLNs, probably due to their localization within the constrained intestinal lamina propria. Lastly, the smaller ILFs, also found within the lamina propria, form only after birth during bacterial colonization of the gut. ${ }^{8}$ These differences in the timing of appearance furthermore reflect the programmed (mLNs, PPs) vs. the environmentinduced (ILFs) development of intestinal lymphoid tissues. This review will now analyze our knowledge of these processes and discuss the consequences on intestinal immunity and homeostasis.

\section{PROGRAMMED LYMPHOIDTISSUES}

Programmed intestinal lymphoid tissues fall into two types. One of them, the PPs, are bound to the intestinal epithelium and connect to the lymphatic system through efferent vessels. They collect antigens directly from the intestinal lumen through specialized epithelial cells, the microfold (M) cells. The other type, the mLNs, is connected like any other LN to the lymphatic system through afferent and efferent vessels, and collect antigens and cells from the lymph drained from the intestines. The development of PPs and LNs has been studied mostly independently, and has shown fascinating differences.

${ }^{1}$ Institut Pasteur, Laboratory of Lymphoid Tissue Development, CNRS URA1961, Paris, France. Correspondence: G Eberl (gerard.eberl@pasteur.fr)

Received 20 July 2009; accepted 11 August 2009; published online 9 September 2009. doi:10.1038/mi.2009.114 


\section{The development of PPs}

The first observations, the model, and the questions. A first glimpse into the fetal development of PPs has been provided by Nishikawa and colleagues. ${ }^{10}$ Using whole-mount immunohistology of mouse fetal intestines, it was shown that vascular cell adhesion molecule (VCAM) $-1^{+}$stromal cells form a dozen of compact clusters along the intestine starting E15.5, followed 1-2 days later by the accumulation of interleukin (IL)$7 \mathrm{R} \alpha^{+} \mathrm{CD} 4{ }^{+}$cells of lymphoid morphology. The first B and $\mathrm{T}$ cells are not found in the PP anlagen before E18.5. In aly/aly mice that lack a functional nuclear factor- $\kappa \mathrm{B}(\mathrm{NF}-\kappa \mathrm{B})$-inducing kinase required in the alternative NF- $\kappa \mathrm{B}$ pathway, it was found that none of these processes take place. ${ }^{11}$ These seminal findings are linked to the earlier observations that mice deficient in lymphotoxin LT $\alpha^{12}$ or LT $\beta,{ }^{13}$ and mice treated with LT $\beta R$-Ig fusion protein ${ }^{14}$ all lack PPs, showing that the membrane form of lymphotoxin, the heterotrimer LT $\alpha_{1} \beta_{2}$ and ligand of LT $\beta R$, is critical for PP development. Signaling through LT $\beta R$ activates both the canonical and the alternative NF- $\kappa B$ pathways. ${ }^{15}$ The alternative pathway leads via NF- $\kappa \mathrm{B}$-inducing kinase to the expression of CXCL13, or B-lymphocyte chemoattractant, which is required in PP development for the recruitment of IL-7R $\alpha^{+} \mathrm{CD} 4{ }^{+}$cells and B cells. ${ }^{16,17}$ The IL$7 \mathrm{R} \alpha^{+} \mathrm{CD} 4^{+}$cells turned out to be a subset of lymphoid tissue inducer (LTi) cells that are critical for PP development through their expression of $\mathrm{LT} \alpha_{1} \beta_{2}{ }^{18}$ Nishikawa and colleagues ${ }^{11}$ also showed that IL-7R $\alpha$-deficient mice failed to develop PPs. In the absence of IL-7R $\alpha$ signaling, LTi cells fail to upregulate $\mathrm{LT} \alpha_{1} \beta_{2},{ }^{19}$ and thus cannot induce LT $\beta$ R signaling and PP development.

These observations led to a three-step model of PP development (Figure 1). ${ }^{20}$ Step I is the induction of organizing centers for PP. An initiator produces an IL-7R $\alpha$ ligand, IL-7 or thymic stromal-derived lymphopoietin. This activates LTi cells (originally termed "inducer of organizing centers"), which in turn activate PP-organizing centers. The PP organizers (or lymphoid tissue organizer LTo cells) are of mesenchymal origin ${ }^{21}$ and similar in phenotype and function to fibroblastic stromal cells found in adult lymphoid tissues (or lymphoid stromal cells) that also express CXCL13. ${ }^{22,23}$ Step II is characterized by architecture formation. Hematopoietic cells, including LTi cells, F4/80 ${ }^{+}$cells, and $\mathrm{CD} 11 \mathrm{c}^{+}$cells, accumulate in the organizing centers, and high endothelial venules are formed. Final step III is characterized by B- and T-cell homing to the growing PPs. Remarkably, this model is still valid 10 years later and emphasizes the problems we still face in understanding the early steps of PP formation. In particular, the initiation of PP development remains unclear. The local source of IL-7 or thymic stromal-derived lymphopoietin remains unidentified and IL-7R $\alpha$-mediated activation of LTi cells can occur in the blood, ${ }^{19}$ as they travel to the intestine from the liver where they are generated. ${ }^{24,25}$ Furthermore, it is also accepted that LTi cells are recruited to PP anlagen by CXCL13 produced by LTo cells upon LT $\beta$ R-mediated activation, ${ }^{9}$ but how this recruitment is actually initiated is not elucidated. Intriguing also is the patterning of PPs along the intestine. Are the positions of PPs pre-determined or stochastically induced? The solutions to these challenging problems should lead, eventually, to the unmasking of the all-powerful initiator.

On the critical role of LTi cells in PP development. Although little progress has been made on the identity and origin of LTo cells, much has been learned about LTi cells in PP development. Two sets of experiments showed that LTi cells deserve their name and are critical to PP development. In the first set, purified LTi cells were shown to rescue PP development in otherwise PP-deficient $\mathrm{CXCR}^{-1-}$ mice, ${ }^{26}$ the receptor for CXCL13 expressed by LTi cells. According to that same study, CXCR5 regulates the activation of integrin $\alpha_{4} \beta_{1}$ on LTi cells, and binding of integrin $\alpha_{4} \beta_{1}$ to vascular cell adhesion molecule- $1^{+}$allows the interaction of LTi cells with LTo cells and the subsequent activation of LTo cells. The second set was based on the earlier finding that the nuclear hormone receptor ROR $\gamma$ is required for LN and PP development. ${ }^{27}$ It was shown that the ROR $\gamma$ t isoform, encoded within the same Rorc locus, was responsible for this phenotype and specifically expressed by LTi cells in the fetus. ${ }^{18}$ In the absence of ROR $\gamma \mathrm{t}$, LTi cells are not generated, and PPs fail to develop. ROR $\gamma \mathrm{t}$ is a transcription factor shown to regulate cell cycle and survival of immature $\mathrm{CD} 4{ }^{+} \mathrm{CD} 8{ }^{+}$thymocytes through $\mathrm{p} 27^{\mathrm{kip}}$ and $\mathrm{Bcl}-\mathrm{x}_{\mathrm{L}}$, respectively, ${ }^{27}$ and expression of the pro-inflammatory cytokine IL-17 in T cells. ${ }^{28}$ The genes regulated by ROR $\gamma \mathrm{t}$ in fetal LTi cells and that are required for their generation remain, however, unknown. Interestingly, IL-17 is expressed in adult intestinal LTi cells, ${ }^{29}$ as well as in LTi-like cells that are isolated from adult spleen ${ }^{30}$ and human fetal LNs. ${ }^{31}$ The significance of IL-17 expression by LTi cells during PP development is unclear, as IL-17- or IL-17R-deficient mice develop LNs and PPs (our unpublished observations). Another interesting but still theoretical possibility is that the activity of ROR $\gamma \mathrm{t}$, and thus PP development, is regulated by a hormone-like compound. Evidence exist that the circadian regulator melatonin is a ligand of the related $\operatorname{ROR} \alpha$ and $\operatorname{ROR} \beta$ nuclear receptors, ${ }^{32,33}$ but a ROR $\gamma$ t ligand remains to be discovered. Finally, also lacking PPs are mice deficient for the transcription regulator Id 2,34 which allows for the generation of LTi cells by inhibiting the basic helix-loop-helix transcription factor E2A. ${ }^{35}$

A nervous twist to PP development. Recently, it was shown that the receptor tyrosine kinase RET, required for the formation of the enteric nervous system, is also required in PP development. ${ }^{36}$ According to the authors, "colonization of the embryonic gut by lymphoid cells and their aggregation to form PPs is reminiscent of the invasion of the gut mesenchyme by neuroectodermal cells that colonize the gut and coalesce to form enteric ganglia." This idea proposes that the patterning of PP development is a consequence of the patterning of the enteric nervous system. However, this hypothesis is dismissed, as mice homozygote for the hypomorphic allele Ret $^{51}$ retain a normal nervous system in the small intestine, yet develop significantly less PPs. Surprisingly, RET is not expressed by the usual IL-7R $\alpha^{+}$ LTi cells, but by CD $45^{+}$hematopoietic IL-7R $\alpha^{-}$CD $11 c^{+}$cells, which also express higher levels of $\mathrm{LT} \alpha_{1} \beta_{2}$ than do the IL-7R $\alpha^{+}$ LTi cells. The presence of IL-7R $\alpha^{-}$CD $11 \mathrm{c}^{+}$cells in PP anlagen has been described earlier, ${ }^{20}$ but because of their lack of IL-7R $\alpha$ and the absence of PPs in IL-7R $\alpha$-deficient mice, ${ }^{11}$ they have 


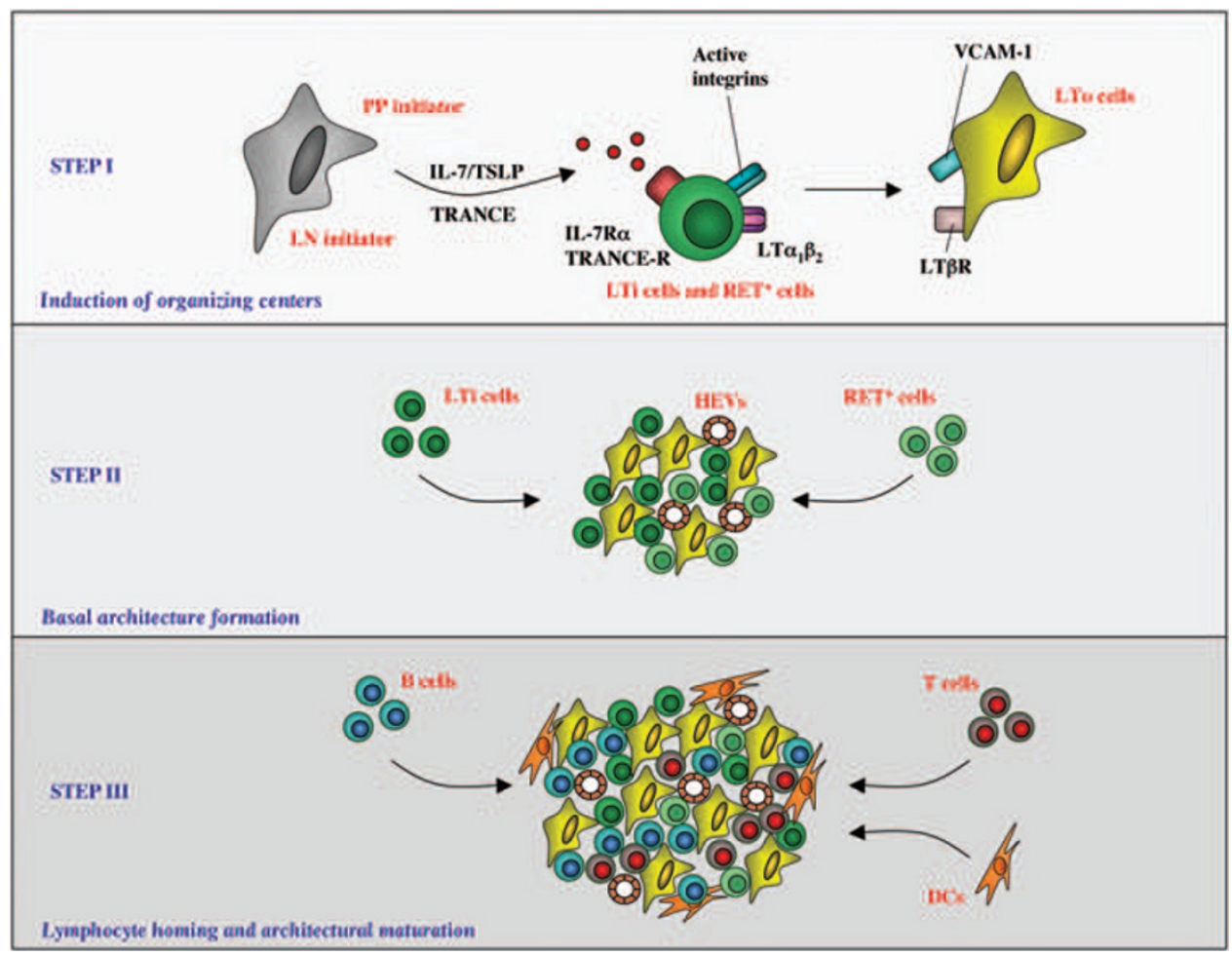

Figure 1 The three steps of Peyer's patch (PP) and lymph node (LN) development. The development of PPs can be described as a three-step process. ${ }^{20}$ During step I, an initiator cell expresses interleukin (IL)-7 or thymic stromal-derived lymphopoietin (TSLP), which induce lymphoid tissue inducer ( $\mathrm{LTi}$ ) cells to express the membrane form of lymphotoxin, $\mathrm{LT} \alpha_{1} \beta_{2}$, and activate lymphoid tissue organizer (LTo) cells through LT $\beta R$. Activation of LTo cells leads to the expression of adhesion molecules, such as vascular cell adhesion molecule (VCAM)- $1^{+}$, as well as the chemokines CXCL13, CCL19, and CCL21 required for lymphoid tissue formation. During step II, a PP anlage develops with a growing mass of LTi and LTo cells, as well as the formation of high endothelial venules (HEVs). During step III, newly generated B and T cells, as well as dendritic cells (DCs), are recruited and segregated into distinct zones. In addition to "conventional" LTi cells, RET ${ }^{+}$CD11 $\mathrm{c}^{+}$cells are also required for PP development. These cells are recruited through RET ligands produced by LTo cells, and express high levels of $L T \alpha_{1} \beta_{2}$. A similar sequence of events unfolds during mesenteric $L N$ development, except that TRANCE rather than IL-7 or TSLP is critical for the activation of LTi cells.

been largely ignored. The IL-7R $\alpha^{-} \mathrm{CD} 11 \mathrm{c}^{+} \mathrm{RET}^{+}$cells are recruited by beads coated with artemin, one of the RET ligands, and mice deficient in GFR $\alpha 3$, the RET co-receptor that provides artemin specificity to the receptor complex, show reduced PP development. The absence of RET or GFR 23 had no effect on the generation of IL-7R $\alpha^{+}$or IL-7R $\alpha^{-}$LTi cells. As artemin is expressed by vascular cell adhesion molecule- $1^{+}$LTo cells, the RET system might rather be involved in the recruitment of IL-7R $\alpha^{-} \mathrm{CD} 11 \mathrm{c}^{+} \mathrm{RET}^{+}$cells to PP anlagen, and possibly also in their activation and $\mathrm{LT} \alpha_{1} \beta_{2}$ expression. Together with IL-7R $\alpha^{+}$LTi cells, these cells may activate LTo cells and induce further PP development (Figure 1). However, the rules governing the patterning of PPs still remain to be uncovered.

\section{The development of $\mathrm{mLNs}$}

The discovery of LTi cells. Mebius et al..$^{37}$ reported in 1996 that "an unusual subset of $\mathrm{CD} 4^{+} \mathrm{CD} 3^{-}$cells" colonizes mLN and peripheral LN anlagen in mouse fetuses. These cells express the integrin $\alpha_{4} \beta_{7}$ and are collected by LN anlagen that express mucosal addressin cell adhesion molecule-1, the ligand of integrin $\alpha_{4} \beta_{7}$. After birth, LNs but not PPs switch to the expression of peripheral lymph node addressin, which collects cells that express CD62L. This first study was followed up by characteriza- tion of the $\mathrm{CD} 4{ }^{+} \mathrm{CD} 3^{-}$cells and their potential role in $\mathrm{LN}$ development. ${ }^{38} \mathrm{CD} 4{ }^{+} \mathrm{CD} 3^{-}$cells express IL-7R $\alpha$ and c-kit, but no lineage markes, as well as $\mathrm{LT} \alpha_{1} \beta_{2}$ and CXCR5. Given the known role of IL-7R $\alpha$, LT $\alpha$, LT $\beta$ and CXCR5 in LN development, ${ }^{9}$ it was concluded that these fetal $\mathrm{CD} 4{ }^{+} \mathrm{CD}^{-}{ }^{-}$cells were required for LN development, and were later defined as LTi cells. These initial studies and hypotheses were corroborated by the discovery of ROR $\gamma \mathrm{t}$ as a specific fetal marker for LTi cells, and by the lack of LTi cells and LNs in ROR $\gamma \mathrm{t}$-deficient mice. ${ }^{18}$ However, ROR $\gamma \mathrm{t}^{+}$cells in LN and PP anlagen include both $\mathrm{CD} 4^{+}$and $\mathrm{CD} 4^{-}$cells, as described for IL-7R $\alpha^{+}$cells in PP anlagen, ${ }^{20}$ which express comparable levels of LT $\alpha$ and LT $\beta$. Although the $\mathrm{CD}^{+}{ }^{+} \mathrm{CD}^{-}$phenotype has been extensively used to characterize LTi cells in the absence of the ROR $\gamma$ t reporter, ${ }^{9}$ the individual roles and lineage relationship of the $\mathrm{CD} 4^{+}$and $\mathrm{CD} 4^{-}$ LTi cell subpopulations remain largely unknown.

Distinct pathways in PP and $\mathrm{mLN}$ development. The development of both LNs and PPs depends on the generation of LTi cells and the activation of LT $\beta$ R-mediated signaling in LTo cells (Figure 1). Mice deficient in $\mathrm{ROR} \gamma \mathrm{t}^{18}$ or $\mathrm{Id} 2^{34}$ on the one

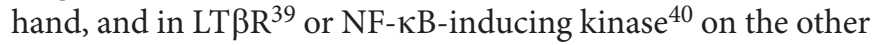
hand, all lack LNs and PPs. However, a deficiency in tumor necrosis factor- $\alpha(\mathrm{TNF} \alpha)$ or TNF receptor-I affects only PP 
development. ${ }^{41,42}$ The basis for this difference in development is unclear. In addition, mice deficient in IL-7R or its associated signaling molecule JAK3 lack PPs and most LNs, whereas small mLNs still develop. ${ }^{43,44}$ In contrast, most LNs, but not PPs, fail to develop in the absence of the TNF superfamily member TRANCE, its receptor TRANCE-R, or its associated signaling molecule TRAF6. ${ }^{45-47}$ However, LN development is rescued in TRAF6-deficient mice by the administration of IL- $7,{ }^{48}$ suggesting that the difference in requirement during $\mathrm{LN}$ vs. PP development is not due to distinct subsets of LTi cells expressing different levels of TRANCE-R or IL-7R $\alpha$, but rather due to the local availability of IL-7 (or TLSP) and TRANCE in PPs and LNs, respectively, which would locally activate LTi cells.

It is actually hard to get rid of mLNs. Although most LNs are absent in mice deficient in LT $\beta,{ }^{13} \mathrm{IL}-7 \mathrm{R},{ }^{44}$, JAK3,${ }^{43}$ CXCR $5,{ }^{16}$ or CXCL13, ${ }^{17} \mathrm{mLN}$ still develop. On the basis of the timely inhibition of LT $\beta$ R signaling using LT $\beta \mathrm{R}-\mathrm{Ig}$ fusion protein, it was shown that mLNs are among the first to initiate development at $\sim$ E11.5. ${ }^{39}$ Whether additional signals are involved in the very early development of LNs is unknown. Alternatively, the development of LNs and PPs in these mutant mice has been assessed in adult mice, which not only have completed their ontogeny of lymphoid tissues but also have acquired a commensal flora. It is therefore possible that the intestinal flora has its part in the development of the draining mLNs, as well as in the TNF-dependent development of PPs, through, for example, recognition of microbe-associated molecular patterns by Toll-like receptors (TLRs) and other innate receptors. Germfree mice bear smaller, somewhat immature lymphoid tissues, ${ }^{8,49,50}$ but the characterization of LN and PP development in mutant germfree mice remains to be undertaken. Discussing the effect of intestinal flora on lymphoid tissue development leads us naturally to the next chapter, the development of inducible intestinal lymphoid tissues.

\section{INDUCIBLE (TERTIARY) LYMPHOIDTISSUES}

Isolated lymphoid follicles are the prototype of intestinal induced lymphoid tissues, described in the small intestine of the mouse only recently, ${ }^{8}$ as well as in other small mammals ${ }^{5,6}$ and in humans. ${ }^{7}$ Similar structures have been documented earlier in lower vertebrates, including amphibians, ${ }^{51}$ reptiles, ${ }^{52}$ and birds ${ }^{53}$ but their inducible nature has been shown only in mice. ${ }^{54,55}$ We have suggested that the pathway used to form ILFs has served as a blueprint for the programmed development of LNs and PPs that did not occur before the advent of mammals. ${ }^{56}$

\section{The development of ILFs}

Cryptopatches, and the inducible and reversible nature of ILFs. The post-birth development and unstable nature of ILFs was first described by Hamada et al. ${ }^{8}$ In mice, ILFs appear only 1-2 weeks after birth as single B-cell follicles surrounded by sheets of dendritic cells. Similar to PPs, they are bound to the intestinal epithelium, collect antigens through $\mathrm{M}$ cells, and develop germinal centers. However, ILFs contain relatively few $\mathrm{T}$ cells and no distinct T-cell zones. Although ILFs are smaller than PPs and not visible macroscopically, their large number (100-200 in the murine small intestine) means they stock an important fraction of intestinal follicular B cells. In extreme circumstances, however, ILFs can swell to the size of individual PP follicles. Such a situation was reported by Fagarasan $e t$ $a l .{ }^{54}$ in mice deficient for the activation-induced deaminase, required for class switch recombination and somatic hypermutation of immunoglobulin genes. These mice produce only germline-encoded IgM, and as a result of a lack of $\operatorname{Ig} \mathrm{A}$ and affinity maturation, they suffer a 100-fold expansion of anaerobe bacteria in the small intestine. Most impressively, in that context, ILFs are hyperplastic and clearly visible by the naked eye on the surface of the intestine. Furthermore, treatment of these mice with antibiotics reduces the flora and normalizes the size of ILFs, showing that ILFs are both inducible and reversible lymphoid tissues.

These data suggested that ILFs are induced to form by the intestinal flora. In germfree mice, ILFs defined as B-cell follicles do not develop, $8,55,57,58$ but are "replaced" by structures containing few B cells and a majority of $\mathrm{Lin}^{-} \mathrm{c}-\mathrm{kit}^{+}$IL-7R $\alpha^{+}$cells, which were later found to be identical to ROR $\gamma \mathrm{t}^{+}$LTi cells. ${ }^{59}$ As a matter of fact, hundreds of small clusters containing less than a thousand cells develop in the intestine of mice, which contain $\mathrm{Lin}^{-} \mathrm{c}-\mathrm{kit}^{+} \mathrm{IL}-7 \mathrm{R} \alpha^{+} \mathrm{ROR} \gamma \mathrm{t}^{+}$cells and are named cryptopatches (CPs) for their localization between crypts. ${ }^{59,60}$ In germfree mice, $\mathrm{CPs}$ do not convert into ILFs but collect more LTi cells. ${ }^{55,61}$ In mice deficient for ROR $\gamma \mathrm{t}$, LTi cells are absent from the intestine, and CPs and ILFs do not form. ${ }^{59,62}$ It was therefore suggested that CPs are clusters of LTi cells that induce the formation of ILFs during colonization of the intestine by bacterial commensals. ${ }^{55,59}$

The development of ILFs from CPs was concluded from the following observations. In specific pathogen-free, germfree, or mutant mice, the number of ILFs might vary, but the total number of ILFs plus CPs, collectively named SILT for "solitary isolated lymphoid tissues," remains a constant. ${ }^{58}$ In addition, CPs develop during the second week after birth ${ }^{60,63}$ in an LT $\alpha$-dependent manner. ${ }^{59}$ When the formation of CPs is blocked by the administration of LT $\beta$ R-Ig fusion protein during the first 2 weeks after birth, the subsequent formation of ILFs is also blocked..$^{55}$ Thus, CPs and ILFs, or SILT, form a modifiable continuum of lymphoid tissues. ${ }^{58}$ The inducible and reversible nature of the CP/ILF or SILT system and its activation by the intestinal flora suggested that it has an important role in intestinal homeostasis. ${ }^{63}$

Finally, it has to be noted that CPs have not yet been reported in humans. As a majority of clinical samples are derived from the colon of weaned and germ-containing patients, we expect that most CPs have converted into ILFs. Thus, an assessment of human CPs should be conducted in newborns.

How bacteria trigger CPs to develop into ILFs. Recent data on the induction of ILF development from CPs (Figure 2) show the following model: Gram-negative commensal bacteria release peptidoglycans during the cell-wall breakdown that is necessary for cell division. Diaminopimelic acid-containing peptidoglycans are recognized by the NOD1 innate receptor in intestinal 


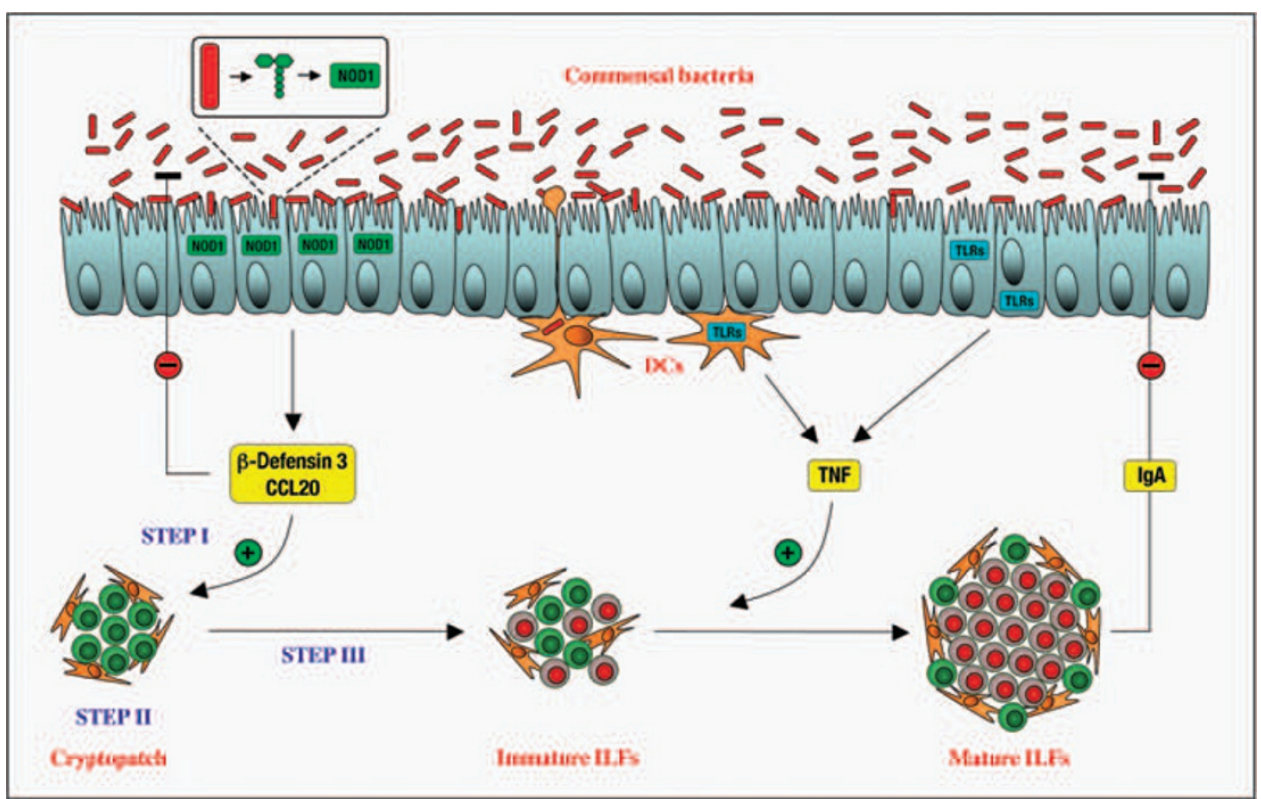

Figure 2 The development of isolated lymphoid follicles (ILFs). Peptidoglycans released mostly by Gram-negative bacteria during cell division are recognized by the NOD1 innate receptor in epithelial cells. Activation of the NOD1 pathway induces expression of CCL20 and $\beta$-defensin-3, both ligands of CCR6 expressed on lymphoid tissue inducer (LTi) cells in cryptopatches (CPs). Ligation of CCR6 activates LTi cells, which induce lymphoid tissue organizer (LTo) cells to express adhesion molecules and chemokines, including CCL20 (step I/II in the sequence of Peyer's patch (PP) and lymph node (LN) development, see Figure 1). Activated CPs recruit CCR6 ${ }^{+}$B cells to form immature ILFs (step III), which further grow into mature B-cell follicles with the help of tumor necrosis factor- $\alpha$ (TNF $\alpha$ ) produced by dendritic cells (DCs) and macrophages upon recognition of bacterial compounds through innate receptors such as Toll-like receptors (TLRs). Mature ILFs generate IgA-producing B cells that target the microbiota. The CP/ILF system works as a self-regulating negative feedback loop, where the induction of ILFs by bacteria leads to increased inhibition of bacteria through the consequent induction of IgA.

epithelial cells, ${ }^{64}$ which then express CCL20 and $\beta$-defensin $3,{ }^{55}$ both CCR6 ligands, and the latter is also an anti-bacterial peptide. ${ }^{65}$ These might directly activate LTi cells in CPs, which express CCR6, to engage LTo cells and recruit CCR6 ${ }^{+} \mathrm{B}$ cells ${ }^{66}$ to CPs. CCL20 can also be expressed by LTo cells, as coculture of LTi cells with intestinal stromal cells induces the expression of CCL20 by stromal cells. ${ }^{62}$ Furthermore, the addition of lipopolysaccharide to these cultures increased the production of chemokines and adhesion molecules by stromal cells, suggesting that bacterial compounds also boost the formation of ILFs through recognition by TLRs. It appears that innate receptors such as TLR2 and TLR4 do not trigger the formation of ILFs from CPs, but rather induce, through TNF $\alpha$, the maturation of growing ILFs into full-blown lymphoid tissues that also bear germinal centers. ${ }^{55,57}$

ILFs in IgA production and intestinal homeostasis. ILFs induced by the commensal bacteria profoundly affect the bacterial community itself. In the absence of ILFs in LT $\beta$ R-Ig-treated animals, the bacterial flora expands more than 10 -fold. ${ }^{55}$ Thus, bacteria and the CP/ILF system are locked into an activation/inhibition or negative feeback loop, which is a basic regulatory system to maintain homeostasis. Indeed, the higher the number of bacteria present in the intestine, the more ILFs are induced; but the more ILFs are induced, the more bacteria are targeted by the immune response initiated in ILFs, and the less bacteria are able to induce ILFs. However, what is the effector arm of ILFs?
It is IgA, shown to have a major role in intestinal homeostasis ${ }^{54}$ through containment of the commensals. ${ }^{67}$

ILFs are populated by "conventional" $\mathrm{CD}^{-} \mathrm{B}-2$ cells, similar to follicular B cells found in PPs and LNs. ${ }^{8}$ Most are naive $\operatorname{IgD}^{+}$ $\mathrm{IgM}^{+}$cells, and $\sim 10 \%$ of ILF B cells express IgA, similar to the proportions found in PPs and suggesting a similar function of $\mathrm{B}$ cells in both compartments. In terms of IgA production, bone marrow chimeric mice that possess ILFs, but not PPs and LNs, can produce Salmonella typhimurium-specific IgA in response to Salmonella infection. ${ }^{68}$ Furthermore, ROR $\gamma \mathrm{t}$-deficient mice that lack all gut-associated lymphoid tissues and generate few $\mathrm{IgA}^{+} \mathrm{B}$ cells (at least during the first 2 months of life) generate normal numbers of $\operatorname{IgA}{ }^{+} \mathrm{B}$ cells when reconstituted with normal bone marrow (to form ILFs), but not ROR $\gamma \mathrm{t}$-deficient bone marrow (that cannot form ILFs). ${ }^{62}$ These data show that ILFs generate IgA-producing B cells, and can do it in the absence of PPs. However, in contrast to PPs, ILFs can also be a site for T-cell-independent generation of IgA. ${ }^{62}$ In TCR $\beta$ - and TCR $\delta$ double-deficient mice, little AID is expressed and few $\operatorname{IgA}^{+}$cells localize in PP follicles, whereas $\mathrm{AID}^{+} \mathrm{B}$ cells and $\mathrm{IgA}^{+}$cells are found in ILFs. It can be noted that, no T-cell zone and few $\mathrm{T}$ cells are present in ILFs, ${ }^{8,59}$ setting the stage for T-cell-independent IgA production. In addition, the number of $\mathrm{AID}^{+} \mathrm{B}$ cells and IgA ${ }^{+}$cells is increased in ILFs of T-cell-deficient mice compared with wild-type mice. ${ }^{62}$ This relative compensation of PP function by ILFs is also observed in mice treated in utero 


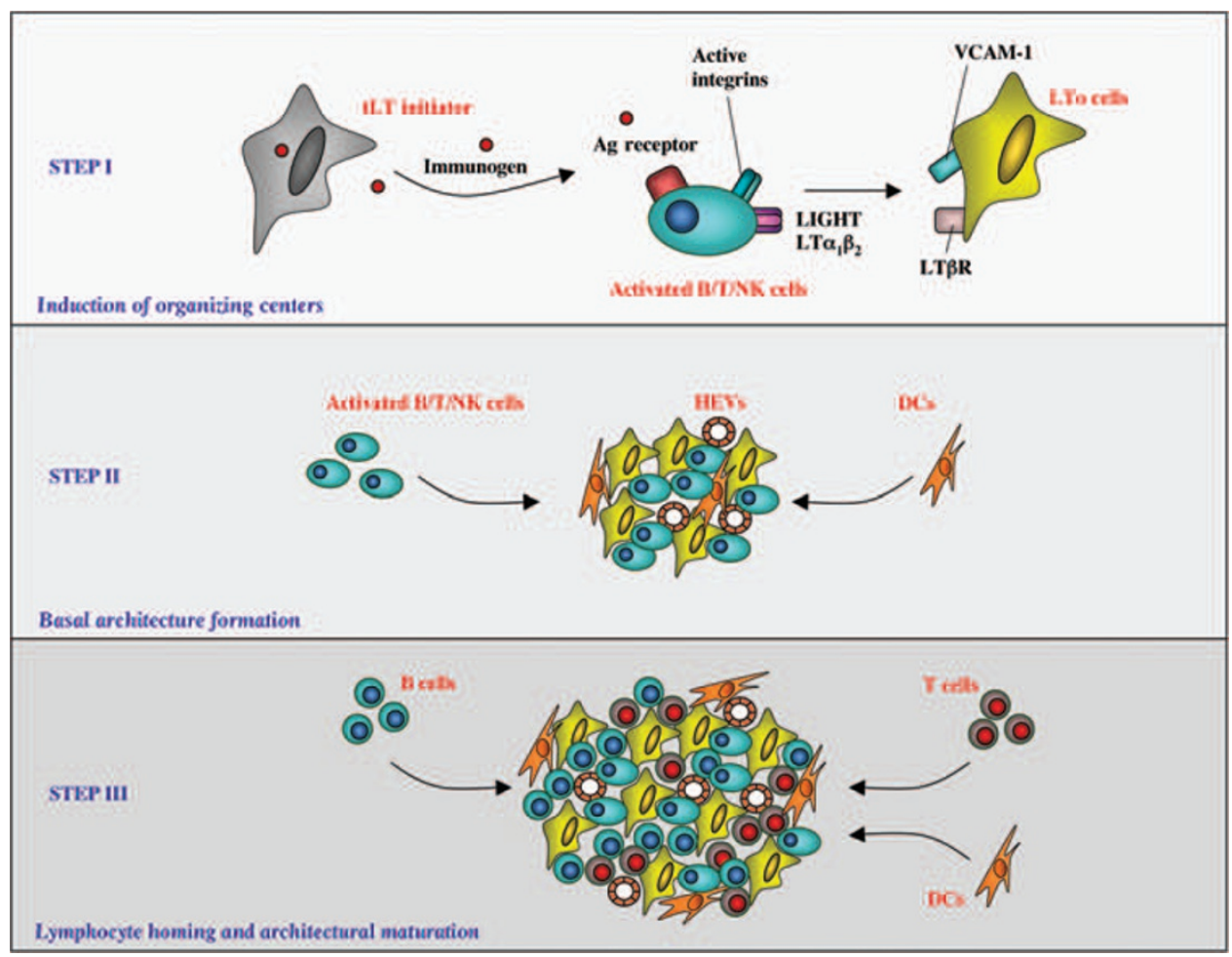

Figure 3 The development of tertiary lymphoid tissues (tLTs). As during Peyer's patch (PP) and lymph node (LN) development, the process of tLT formation can be described as a three-step process. During step I, an initiator, such as an antigen-presenting cell or an infected/injured cell, activates antigen-specific lymphocytes or natural killer (NK) cells. Upon migration into the inflamed tissue, the effector lymphocytes activate lymphoid tissue organizer (LTo) cells through LT $\beta$ R to express adhesion molecules and chemokines. During step II, additional effectors and dendritic cells (DCs) are recruited to the inflammatory site, and contribute to establish a structure resembling a LN anlage, which also develops high endothelial venules (HEVs). During step III, naive B and T cells and DCs are recruited to form a tLT that has the ability to generate de novo adaptive immune responses and perpetuate local inflammation.

with LT $\beta R$-Ig fusion protein that do not develop PPs and LNs, however, develop larger and more numerous ILFs. ${ }^{57}$

\section{The development of tertiary lymphoid tissues}

Lymphoid tissue neogenesis during inflammation. Given their inducible nature, ILFs are tertiary lymphoid tissues (tLTs) (whereas PPs, LNs, and spleen are secondary lymphoid tissues). Nevertheless, the starting point of their development, the $\mathrm{CP}$, is programmed. ${ }^{55,60} \mathrm{An}$ abundant literature documents the formation of tLTs during chronic autoimmune inflammations, both in mice and humans. ${ }^{69}$ The best studied of these inflammation-induced tLTs are iBALTs, or induced bronchusassociated lymphoid tissues. ${ }^{70}$ In splenectomized LT $\alpha$-deficient mice that lack all secondary lymphoid tissues, an influenza virus infection generates robust $\mathrm{B}$ - and $\mathrm{T}$-cell responses that appear to be primed in numerous iBALT-bearing germinal centers. Such iBALTs can also be induced, although to smaller sizes, in wild-type mice, but are absent in non-infected mice. Importantly, iBALTs also develop in the absence of ROR $\gamma \mathrm{t}$, and thus independently of "conventional" LTi cells. During inflammation, the function of LTi cells could therefore be transferred to other infiltrating lymphoid cells, such as B cells expressing $\mathrm{LT} \alpha_{1} \beta_{2}{ }^{17}$ or T cells expressing LIGHT, another ligand of LT $\beta R .^{71}$ In the latter case, T cells were shown to induce the formation of tLTs in the pancreas of aged nonobese diabetic (NOD) mice (Figure 3).

In the colon, numerous tLTs are induced upon treatment of LT $\alpha$-deficient mice with dextran sodium sulfate. ${ }^{72}$ It was not assessed whether formation of these colonic tLTs is dependent on LTi cells, but their formation in the absence of LT $\alpha$ might suggest so. Colonic tLTs and ILFs have similar structures, yet ILFs do not develop in the absence of LT $\alpha .^{59}$ Thus, two distinct types of tLTs might develop in the colon, as well as in the small intestine, one that is induced from CPs by bacteria and another that is induced by inflammation independently of CPs. As a last note, colonic ILFs might also be confused with colonic PPs, which in the mouse contain only 2-3 follicles compared with the usual five found in PPs of the small intestine (our unpublished observations).

\section{CONCLUSION}

The intestine is monitored by a vast network of lymphoid tissues, which are in part programmed to develop during fetal life, and in part induced to develop after birth in response to commensal bacteria and inflammation. The programmed development of PPs and mLNs is a late event in evolution as only mammals do, but adds a level of readiness to the immune system when faced with intestinal pathogens and injury. The induced 
lymphoid tissues, such as ILFs and inflammatory tLTs, add the necessary flexibility to the immune system to adapt to the large, diverse, and changing community of commensal and pathogenic microbes. The role for the intestinal immune system is obviously not to eliminate all germs from the lumen, as commensal bacteria are required for optimal digestion, defense against pathogens, and protection against tumors. Rather, the intestinal immune system has to establish a workable equilibrium between self and commensals so as to build the most efficient combination, in what has been named a "superorganism." ${ }^{73}$ How the intestinal immune system distinguishes between harmless commensals and harmful pathogens, and acts to contain the former and destroy the latter, is a matter of blurry reality.

\section{DISCLOSURE}

The authors declare no conflict of interest.

\section{(C) 2009 Society for Mucosal Immunology}

\section{REFERENCES}

1. Ambrose, C.T. Immunology's first priority dispute-an account of the 17th-century Rudbeck-Bartholin feud. Cell Immunol 242, 1-8 (2006).

2. Dobson, G.E. On the presence of Peyer's patches (Glandulae Agminatae) in the caecum and colon of certain mammals. J Anat Physiol 18, 388-392 (1884).

3. Borisov, A.V. (Lymphatic capillaries and vessels in the milk spots of the human greater omentum.). Arkh Anat Gistol Embriol 44, 115-120 (1963).

4. Rangel-Moreno, J. et al. Omental milky spots develop in the absence of lymphoid tissue-inducer cells and support $B$ and $T$ cell responses to peritoneal antigens. Immunity 5, 731-743 (2009).

5. Keren, D.F., Holt, P.S., Collins, H.H., Gemski, P. \& Formal, S.B. The role of Peyer's patches in the local immune response of rabbit ileum to live bacteria. J Immunol 120, 1892-1896 (1978).

6. Rosner, A.J. \& Keren, D.F. Demonstration of M cells in the specialized follicle-associated epithelium overlying isolated lymphoid follicles in the gut. J Leukoc Bio/ 35, 397-404 (1984).

7. Moghaddami, M., Cummins, A. \& Mayrhofer, G. Lymphocyte-filled villi: comparison with other lymphoid aggregations in the mucosa of the human small intestine. Gastroenterology 115, 1414-1425 (1998).

8. Hamada, H. et al. Identification of multiple isolated lymphoid follicles on the antimesenteric wall of the mouse small intestine. J Immuno/ 168, 57-64 (2002).

9. Mebius, R.E. Organogenesis of lymphoid tissues. Nat Rev Immuno/3, 292-303 (2003).

10. Adachi, S., Yoshida, H., Kataoka, H. \& Nishikawa, S. Three distinctive steps in Peyer's patch formation of murine embryo. Int Immuno/ 9, 507-514 (1997).

11. Adachi, S. et al. Essential role of IL-7 receptor $\alpha$ in the formation of Peyer's patch anlage. Int Immunol 10, 1-6 (1998).

12. De Togni, P. et al. Abnormal development of peripheral lymphoid organs in mice deficient in lymphotoxin. Science 264, 703-707 (1994).

13. Koni, P.A. et al. Distinct roles in lymphoid organogenesis for lymphotoxins $\alpha$ and $\beta$ revealed in lymphotoxin $\beta$-deficient mice. Immunity $6,491-500$ (1997).

14. Rennert, P.D., Browning, J.L., Mebius, R., Mackay, F. \& Hochman, P.S. Surface lymphotoxin $\alpha / \beta$ complex is required for the development of peripheral lymphoid organs. J Exp Med 184, 1999-2006 (1996).

15. Dejardin, E. et al. The lymphotoxin- $\beta$ receptor induces different patterns of gene expression via two NF-kappaB pathways. Immunity 17, 525-535 (2002).

16. Forster, R. et al. A putative chemokine receptor, BLR1, directs $B$ cell migration to defined lymphoid organs and specific anatomic compartments of the spleen. Cell 87, 1037-1047 (1996).

17. Ansel, K.M. et al. A chemokine-driven positive feedback loop organizes lymphoid follicles. Nature 406, 309-314 (2000).

18. Eberl, G. et al. An essential function for the nuclear receptor ROR $\mathrm{R}$ t in the generation of fetal lymphoid tissue inducer cells. Nat Immuno/ 5, 64-73 (2004).
19. Luther, S.A., Ansel, K.M. \& Cyster, J.G. Overlapping roles of CXCL13, interleukin 7 receptor $\alpha$ and CCR7 ligands in lymph node development. J Exp Med 197, 1191-1198 (2003).

20. Yoshida, H. et al. IL-7 receptor $\alpha^{+}$CD3 $^{-}$cells in the embryonic intestine induces the organizing center of Peyer's patches. Int Immunol 11, 643-655 (1999).

21. Honda, K. et al. Molecular basis for hematopoietic/mesenchymal interaction during initiation of Peyer's patch organogenesis. J Exp Med 193, 621-630 (2001)

22. Cyster, J.G. et al. Follicular stromal cells and lymphocyte homing to follicles. Immunol Rev 176, 181-193 (2000).

23. Peduto, L. et al. Inflammation recapitulates the ontogeny of lymphoid stromal cells. J Immunol 182, 5789-5799 (2009).

24. Yoshida, H. et al. Expression of $\alpha 4 \beta 7$ integrin defines a distinct pathway of lymphoid progenitors committed to T cells, fetal intestinal lymphotoxin producer, NK, and dendritic cells. J Immunol 167, 2511-2521 (2001).

25. Mebius, R.E. et al. The fetal liver counterpart of adult common lymphoid progenitors gives rise to all lymphoid lineages, CD45+CD4+CD3 - cells, as well as macrophages. J Immunol 166, 6593-6601 (2001).

26. Finke, D., Acha-Orbea, H., Mattis, A., Lipp, M. \& Kraehenbuhl, J. CD4 ${ }^{+} \mathrm{CD} 3^{-}$cells induce Peyer's patch development: role of $\alpha_{4} \beta_{1}$ integrin activation by CXCR5. Immunity 17, 363-373 (2002).

27. Sun, Z. et al. Requirement for ROR $\gamma$ in thymocyte survival and lymphoid organ development. Science 288, 2369-2373 (2000).

28. Ivanov, II. et al. The orphan nuclear receptor ROR $\gamma$ t directs the differentiation program of proinflammatory IL-17+ Thelper cells. Cel/ 126, 1121-1133 (2006)

29. Sanos, S.L. et al. RORgammat and commensal microflora are required for the differentiation of mucosal interleukin 22-producing NKp46+ cells. Nat Immunol 10, 83-91 (2009).

30. Takatori, H. et al. Lymphoid tissue inducer-like cells are an innate source of IL-17 and IL-22. J Exp Med 206, 35-41 (2009).

31. Cupedo, T. et al. Human fetal lymphoid tissue-inducer cells are interleukin 17-producing precursors to RORC+CD127+ natural killer-like cells. Nat Immunol 10, 66-74 (2009).

32. Missbach, M. et al. Thiazolidine diones, specific ligands of the nuclear receptor retinoid $Z$ receptor/retinoid acid receptor-related orphan receptor $\alpha$ with potent antiarthritic activity. J Biol Chem 271, 13515-13522 (1996).

33. Klosen, P. et al. The $\mathrm{mt} 1$ melatonin receptor and ROR $\beta$ receptor are co-localized in specific TSH-immunoreactive cells in the pars tuberalis of the rat pituitary. J Histochem Cytochem 50, 1647-1657 (2002).

34. Yokota, Y. et al. Development of peripheral lymphoid organs and natural killer cells depends on the helix-loop-helix inhibitor Id2. Nature 397, 702-706 (1999).

35. Boos, M.D., Yokota, Y., Eberl, G. \& Kee, B.L. Mature natural killer cell and lymphoid tissue-inducing cell development requires Id2-mediated suppression of E protein activity. J Exp Med 204, 1119-1130 (2007).

36. Veiga-Fernandes, $\mathrm{H}$. et al. Tyrosine kinase receptor RET is a key regulator of Peyer's patch organogenesis. Nature 446, 547-551 (2007).

37. Mebius, R.E., Streeter, P.R., Michie, S., Butcher, E.C. \& Weissman, I.L. A developmental switch in lymphocyte homing receptor and endothelial vascular addressin expression regulates lymphocyte homing and permits CD4 ${ }^{+} \mathrm{CD}^{-}$cells to colonize lymph nodes. Proc Natl Acad Sci USA 93, 11019-11024 (1996)

38. Mebius, R.E., Rennert, P. \& Weissman, I.L. Developing lymph nodes collect $\mathrm{CD} 4^{+} \mathrm{CD} 3^{-} \mathrm{LT} \beta^{+}$cells that can differentiate to APC, NK cells, and follicular cells but not T or B cells. Immunity 7, 493-504 (1997).

39. Rennert, P.D., James, D., Mackay, F., Browning, J.L. \& Hochman, P.S. Lymph node genesis is induced by signaling through the lymphotoxin $\beta$ receptor. Immunity 9, 71-79 (1998)

40. Miyawaki, S. et al. A new mutation, aly, that induces a generalized lack of lymph nodes accompanied by immunodeficiency in mice. Eur J Immunol 24, 429-434 (1994).

41. Neumann, B., Luz, A., Pfeffer, K. \& Holzmann, B. Defective Peyer's patch organogenesis in mice lacking the $55-\mathrm{kD}$ receptor for tumor necrosis factor. J Exp Med 184, 259-264 (1996).

42. Korner, H. et al. Distinct roles for lymphotoxin- $\alpha$ and tumor necrosis factor in organogenesis and spatial organization of lymphoid tissue. Eur $J$ Immunol 27, 2600-2609 (1997).

43. Park, S.Y. et al. Developmental defects of lymphoid cells in Jak3 kinasedeficient mice. Immunity 3, 771-782 (1995). 
44. Cao, X et al. Defective lymphoid development in mice lacking expression of the common cytokine receptor gamma chain. Immunity 2, 223-238 (1995).

45. Kim, D. et al. Regulation of peripheral lymph node genesis by the tumor necrosis factor family member TRANCE. J Exp Med 192, 1467-1478 (2000).

46. Kong, Y.Y. et al. OPGL is a key regulator of osteoclastogenesis, lymphocyte development and lymph-node organogenesis. Nature 397, 315-323 (1999).

47. Naito, A. et al. Severe osteopetrosis, defective interleukin-1 signalling and lymph node organogenesis in TRAF6-deficient mice. Genes Cells 4, 353-362 (1999).

48. Yoshida, $H$. et al. Different cytokines induce surface lymphotoxin- $\alpha \beta$ on IL-7 receptor $\alpha$ cells that differentially engender lymph nodes and Peyer's patches. Immunity 17, 823-833 (2002).

49. Talham, G.L., Jiang, H.Q., Bos, N.A. \& Cebra, J.J. Segmented filamentous bacteria are potent stimuli of a physiologically normal state of the murine gut mucosal immune system. Infect Immun 67, 1992-2000 (1999).

50. Mazmanian, S.K., Liu, C.H., Tzianabos, A.O. \& Kasper, D.L. An immunomodulatory molecule of symbiotic bacteria directs maturation of the host immune system. Cell 122, 107-118 (2005).

51. Ardavin, C.F., Zapata, A., Villena, A. \& Solas, M.T. Gut-associated lymphoid tissue (GALT) in the amphibian urodele Pleurodeles waltl. J Morphol 173, 35-41 (1982).

52. Borysenko, M. \& Cooper, E.L. Lymphoid tissue in the snapping turtle, Chelydra serpentina. J Morphol 138, 487-497 (1972)

53. Befus, A.D., Johnston, N., Leslie, G.A. \& Bienenstock, J. Gut-associated lymphoid tissue in the chicken. I. Morphology, ontogeny, and some functional characteristics of Peyer's patches. J Immunol 125, 2626-2632 (1980).

54. Fagarasan, S. et al. Critical roles of activation-induced cytidine deaminase in the homeostasis of gut flora. Science 298, 1424-1427 (2002).

55. Bouskra, D. et al. Lymphoid tissue genesis induced by bacterial commensals regulates intestinal homeostasis. Nature 456, 507-510 (2008).

56. Eberl, G. From induced to programmed lymphoid tissues: the long road to preempt pathogens. Trends Immuno/ 28, 423-428 (2007).

57. Lorenz, R.G., Chaplin, D.D., McDonald, K.G., McDonough, J.S. \& Newberry, R.D. Isolated lymphoid follicle formation is inducible and dependent upon lymphotoxin-sufficient B lymphocytes, lymphotoxin $\beta$ receptor, and TNF receptor I function. J Immunol 170, 5475-5482 (2003).
58. Pabst, O. et al. Adaptation of solitary intestinal lymphoid tissue in response to microbiota and chemokine receptor CCR7 signaling. J Immunol 177, 6824-6832 (2006).

59. Eberl, G. \& Littman, D.R. Thymic origin of intestinal $\alpha \beta$ T cells revealed by fate mapping of ROR $\gamma \mathrm{t}^{+}$cells. Science 305, 248-251 (2004).

60. Kanamori, Y. et al. Identification of novel lymphoid tissues in murine intestinal mucosa where clusters of c-kit+ IL-7R+ Thy ${ }^{+}$lymphohemopoietic progenitors develop. J Exp Med 184, 1449-1459 (1996).

61. Velaga, S. et al. Chemokine receptor CXCR5 supports solitary intestinal lymphoid tissue formation, B cell homing, and induction of intestinal IgA responses. J Immunol 182, 2610-2619 (2009).

62. Tsuji, M. et al. Requirement for lymphoid tissue-inducer cells in isolated follicle formation and T cell-independent immunoglobulin a generation in the gut. Immunity 29, 261-271 (2008).

63. Eberl, G. Inducible lymphoid tissues in the adult gut: recapitulation of a fetal developmental pathway? Nat Rev Immunol 5, 413-420 (2005).

64. Fritz, J.H., Ferrero, R.L., Philpott, D.J. \& Girardin, S.E. Nod-like proteins in immunity, inflammation and disease. Nat Immunol 7, 1250-1257 (2006).

65. Yang, D. et al. Beta-defensins: linking innate and adaptive immunity through dendritic and T cell CCR6. Science 286, 525-528 (1999).

66. McDonald, K.G. et al. CC chemokine receptor 6 expression by B lymphocytes is essential for the development of isolated lymphoid follicles. Am J Pathol 170, 1229-1240 (2007).

67. Macpherson, A.J. \& Uhr, T. Induction of protective IgA by intestinal dendritic cells carrying commensal bacteria. Science 303, 1662-1665 (2004).

68. Lorenz, R.G. \& Newberry, R.D. Isolated lymphoid follicles can function as sites for induction of mucosal immune responses. Ann NY Acad Sci 1029, 44-57 (2004).

69. Aloisi, F. \& Pujol-Borrell, R. Lymphoid neogenesis in chronic inflammatory diseases. Nat Rev Immunol 6, 205-217 (2006).

70. Moyron-Quiroz, J.E. et al. Role of inducible bronchus associated lymphoid tissue (BALT) in respiratory immunity. Nat Med 10, 927-934 (2004).

71. Lee, Y. et al. Recruitment and activation of naive T cells in the islets by lymphotoxin beta receptor-dependent tertiary lymphoid structure. Immunity 25, 499-509 (2006).

72. Spahn, T.W. et al. Induction of colitis in mice deficient of Peyer's patches and mesenteric lymph nodes is associated with increased disease severity and formation of colonic lymphoid patches. Am J Pathol 161, 2273-2282 (2002)

73. Mai, V. \& Draganov, P.V. Recent advances and remaining gaps in our knowledge of associations between gut microbiota and human health. World J Gastroenterol 15, 81-85 (2009). 